\title{
Ainda Eleições de Segunda Ordem? Análise da participação e dos resultados das Eleições Europeias de 2014
}

\section{Still Second-Order Elections? Analysis of the turnout and results of the 2014 European Elections}

\section{BRUNO THEODORO LUCIANO ${ }^{1}$}

Resumo: Os países-membros da União Europeia (UE) realizaram eleições para escolha dos membros do Parlamento Europeu entre os dias 22 e 25 de maio de 2014. Desde o primeiro pleito de natureza europeia, o Parlamento Europeu ganhou sucessivos poderes institucionais dentro da integração europeia, ocupando na atualidade um papel de co-legislador em quase todas as matérias comunitárias. O aumento de relevância dessa instituição ocorre simultaneamente à forte queda no nível de participação dos cidadãos nas eleições. A antecipação da data eleitoral de junho para maio, o contexto conjuntural de crise na zona do euro e o novo papel dos grupos políticos europeus na definição do candidato à Presidente da Comissão Europeia trazem possibilidades de reversão desse quadro de baixa participação popular e de politização das eleições europeias. Discute-se, no presente artigo, se esses novos elementos podem tornar essas eleições verdadeiramente europeias, haja vista a histórica predominância dos assuntos políticos nacionais nas campanhas eleitorais.

Palavras-chave: União Europeia. Parlamento Europeu. Eleições europeias.

Abstract: The European Union (EU) Member States held direct elections to members of the European Parliament from 22 to 25 May 2014. Since the first European elections, the European Parliament has gained successive institutional competences within the European Integration, presenting since the Lisbon Treaty a co-legislative role in almost all communitarian issues. The increase of relevance of this body is observed together with a strong decrease of citizens' turnout in elections. The anticipation of the electoral schedule from June to May, the context of Eurozone crisis, and the new role of European political groups in the definition of the European Commission Presidency bring possibilities of changing the low level of popular turnout and politization in European elections. The present paper discuss if these elections can become truly European, regarding the historic prevalence of domestic political issues within electoral campaigns.

Keywords: European Union. European Parliament. European Elections.

\footnotetext{
${ }^{1}$ Mestre em Relações Internacionais pela Universidade de Brasília (UnB). Konrad Adenauer Fellow em

${ }^{1}$ Mestre em Relações Internacionais pela Universidade de Brasília (UnB). Konrad Adenauer Fellow em
Estudos Europeus no Centro de Relações Internacionais da Fundação Getúlio Vargas (FGV). Endereço: Centro de Relações Internacionais, Fundação Getúlio Vargas, Praia de Botafogo, 190, 14o Andar, CEP: 22250-900. E-mail: bruno.luciano@fgv.br
} 


\section{Introdução}

Os países-membros da União Europeia (UE) realizaram eleições para escolha dos membros do Parlamento Europeu (PE) entre os dias 22 e 25 de maio de 2014. Esta é a oitava vez que os eurodeputados são escolhidos diretamente pelos cidadãos dos países europeus. Constituída nos primeiros anos do processo de integração da Europa, essa instituição parlamentar teve em seus primeiros anos a função de aproximar os legislativos nacionais das decisões e políticas tomadas no âmbito regional, além de exercer um controle político sobre as estruturas executivas comunitárias.

Desde o primeiro pleito de natureza europeia, o Parlamento Europeu, criado como instância parlamentar consultiva, ganhou sucessivos poderes institucionais dentro da integração europeia, ocupando na atualidade um papel de co-legislador em quase todas as matérias comunitárias, excetuando-se temas de política externa, segurança e defesa. Além de ter um poder de supervisão das atividades da Comissão Europeia, o PE tem um papel fundamental na aprovação do orçamento e das finanças comunitárias, bem como no consentimento, aprovação ou rejeição das decisões normativas europeias.

No contexto da integração europeia, a introdução de uma Assembleia Europeia, posteriormente denominada de Parlamento Europeu, foi considerada como resposta imediata para lidar com a questão do déficit democrático no processo integracionista. $\mathrm{O}$ Parlamento, nesse sentido, fora compreendido como órgão defensor e representante da democracia, eficiência, transparência e accountability dentro da UE (Lodge, 1994). O acréscimo de poderes desse órgão de características parlamentares na Europa foi uma resposta padronizada para a eliminação do suposto déficit democrático da integração (Goetze; Rittberger, 2010).

A criação e empoderamento do Parlamento Europeu, somados ao recente fortalecimento do diálogo com os parlamentos nacionais, foram as soluções defendidas pelos grupos políticos do continente para garantir que as instituições europeias fossem compostas pelos mesmos valores e princípios democráticos existentes no plano político nacional. A demanda de construção da democracia representativa em escala europeia levou à necessidade de desenvolvimento de estruturas parlamentares supranacionais, as quais trouxessem legitimidade ao sistema político europeu (Ibidem, 2010).

Essa visão relaciona-se à opinião de que a constituição da Europa deveria representar mais do que uma mera associação de Estados e tribunais, calcadas em estruturas intergovernamentais e tecnocráticas. Deveria apresentar-se como uma associação de seus próprios cidadãos. Nesse sentido, foi possibilitado ao PE tornar-se cada vez mais forte, em termos de competências e poderes no processo decisório europeu, embora as eleições para esse órgão careçam de uma real legitimidade democrática (Brunkhorst, 2006).

O aumento de relevância dessa instituição parlamentar ocorre simultaneamente à forte queda no nível de participação dos cidadãos nas eleições, passando de 61,99\% em 1979 para $43 \%$ nas eleições de 2009. O desconhecimento e descrédito em relação às instituições políticas europeias passam a coexistir com o real aumento de sua relevância política. A antecipação da data eleitoral de junho para maio, o contexto conjuntural de crise nos países da zona do euro e o novo papel dos grupos políticos europeus na definição do candidato à Presidente da Comissão Europeia, órgão executivo e tecnocrático da UE, trouxeram possibilidades de reversão desse quadro de baixa participação popular e politização das eleições europeias.

Discute-se, no presente artigo, se esses novos elementos podem tornar essas eleições verdadeiramente europeias, haja vista a histórica predominância dos assuntos políticos nacionais e domésticos nas campanhas 
eleitorais. Em um primeiro momento, apresenta-se o desenvolvimento de eleições diretas na integração europeia, iniciado em 1979. Posteriormente, o artigo se centra nas eleições europeias de 2014, nas candidaturas apresentadas, bem como nos resultados eleitorais apresentados. A partir desses elementos pretende-se verificar as possibilidades de politização da construção europeia.

\section{Inserção de Eleições Diretas no Parlamento Europeu}

Até o final dos anos 1970, os membros da antiga Assembleia Europeia eram indicados indiretamente pelos congressos nacionais. Com o objetivo de reduzir o suposto déficit de democracia e representatividade das instituições europeias, assim como suscitar a politização dos temas europeus entre a população, foram realizadas pela primeira vez, em junho de 1979, eleições diretas para o Parlamento Europeu.
Embora os princípios democráticos e representativos para a realização das eleições europeias sejam compartilhados por todos os países europeus (sufrágio universal, direto e secreto), predomina-se a diversidade dos sistemas eleitorais nacionais (diversidade de modelos de listas e circunscrições eleitorais). Exemplos disso são as datas eleitorais, as quais são próximas, porém não comuns ${ }^{2}$.

Um dos critérios definidos nos anos 1970 foi o número e a distribuição de vagas por cada Estado-membro a partir das primeiras eleições diretas, indicado pela Tabela 1. Os países pequenos favoreceram-se com a repartição de assentos proposta, a qual reduziu as assimetrias populacionais dentro das bancadas parlamentares europeias, seguindo o princípio da proporcionalidade atenuada. Durante os primeiros anos da então Comunidade Econômica Europeia (CEE), os países do Benelux (Bélgica, Países Baixos e Luxemburgo) dispunham de $24 \%$ dos assentos da Assembleia, embora sua população representasse $12 \%$ do total de habitantes dos países da CEE (Levi, 1966).

\footnotetext{
${ }^{2}$ Enquanto a maioria dos países da Europa tem a tradição de votar aos domingos, países como o Reino Unido e os Países Baixos votam na quinta-feira.
} 
Tabela 1

Distribuição das vagas do Parlamento Europeu por Estado-membro (1958-1979)

\begin{tabular}{lccc}
\hline Estados Membros & $\begin{array}{c}\text { Estados Fundadores } \\
\text { CEE (1958) }\end{array}$ & $1^{\circ}$ Alargamento & Eleições Diretas (1979) \\
& & $(1973)$ &
\end{tabular}

\begin{tabular}{lccc}
\hline Bélgica & 14 & 14 & 24 \\
Dinamarca & - & 10 & 16 \\
Alemanha & 36 & 36 & 81 \\
França & 36 & 36 & 81 \\
\hline Irlanda & - & 10 & 15 \\
Itália & 36 & 36 & 81 \\
\hline Luxemburgo & 6 & 6 & 6 \\
\hline Países Baixos & 14 & 14 & 25 \\
Reino Unido & - & 36 & 81 \\
\hline Total & $\mathbf{1 4 2}$ & $\mathbf{1 9 8}$ & $\mathbf{4 1 0}$
\end{tabular}

Fonte: elaboração própria, baseado em dados do Centre Virtuel de la Connaissance sur l'Europe (CVCE), 2011.

Importante também ressaltar o significativo crescimento do número de deputados europeus a partir da inclusão das eleições diretas. Se comparado ao número de assentos do momento em que houve o primeiro alargamento europeu, o número de eurodeputados após 1979 mais que dobra, provocando um aumento sensível do quadro parlamentar europeu. Ao mesmo tempo em que a legitimidade conferida a essa instituição pelas eleições democráticas permitia um crescimento numérico de parlamentares, esse aumento do corpo parlamentar favoreceria, a partir dos anos seguintes, a especialização, a profissionalização e o aumento das atividades dos eurodeputados.

Por conta do baixo nível de participação eleitoral e da forte concentração das campanhas eleitorais em disputas políticas nacionais, tem-se categorizado as eleições europeias como eleições de segunda ordem, eleições secundárias em relação às eleições para os cargos executivos nacionais (Schmitt, 2005). Além da forte presença de discussões partidárias nacionais, lideradas pelos partidos políticos nacionais, os grandes partidos e os partidos no poder tendem a receber menos votos do que os pequenos partidos. Nesse sentido, as escolhas dos eleitores em eleições dessa natureza são mais polarizadas e ideologizadas, nas quais os cidadãos têm encaminhado seus votos aos partidos que mais se aproximam de suas preferências ideológicas, e não dos partidos de maior expressão política. $\mathrm{O}$ fato de que os partidos políticos nacionais são os atores responsáveis pela seleção e organização da lista de candidatos, bem como das campanhas eleitorais, reforça o caráter nacional e secundário das eleições, esvaziando as características europeias do pleito. 
Até antes das eleições diretas, os parlamentares escolhidos nacionalmente eram virtualmente pró-integracionistas (parlamentares nacionais interessados em temas de integração regional) e, em razão do exercício de duplo mandato (parlamentar nacional e europeu), tinham tempo limitado para suas atividades europeias (Nugent, 1999). Nas primeiras eleições diretas somente $30 \%$ dos parlamentares eleitos ainda tinham duplo mandato, proporção que foi diminuída nos pleitos seguintes (Ibidem).

Desde seu princípio, as eleições europeias foram caracterizadas como um somatório de eleições nacionais, com baixa participação da sociedade (já que a maioria dos países tem instituído o voto facultativo), e preponderância de temas políticos nacionais nas campanhas eleitorais (Bardi; Ignazi, 1999). Com relação aos eurodeputados que passaram a ser diretamente escolhidos, Bardi e Ignazi (ibid) os divide em quatro perfis: ex-dirigentes (políticos que tiveram uma carreira política de uma vida toda e que passariam a trabalhar no PE em uma espécie de aposentadoria); políticos vitrines (pouco interessados nas atividades do Parlamento, mas voltados para a busca por prestígio político); técnicos ou euroespecialistas (políticos com formação especializada nos temas de integração europeia); e jovens políticos (políticos em formação que teriam como primeiro passo na carreira política o cargo de eurodeputado). Importante ressaltar a dependência, nesses perfis, da experiência na política europeia à carreira política nacional, tendo em vista que os candidatos a eurodeputados são exclusivamente selecionados pelos partidos nacionais.

As primeiras eleições diretas tiveram um efeito ambíguo. Ao mesmo tempo em que conferiram ao Parlamento maior legitimidade, haja vista que este órgão se tornou a única instituição comunitária diretamente eleita pelos cidadãos europeus, também criaram expectativas públicas difíceis de serem alcançadas, por conta de seu baixo poder decisório na integração europeia, em comparação ao Conselho da UE e a Comissão (Corbett et al 2003).

Com esse acréscimo de legitimidade, o Parlamento diretamente eleito passou a fazer uso mais intensivo de seus poderes orçamentários. Após a posse dos novos eurodeputados, estes criaram uma subcomissão de assuntos políticos, com o propósito de canalizar as discussões sobre maiores mudanças institucionais na integração europeia, direcionadas a maiores prerrogativas do Parlamento. Ao longo do tempo, essa estrutura parlamentar foi recebendo mais relevância no contexto comunitário, a partir do aumento de recursos para a infraestrutura interna do PE, que passou a ser composto, após suas primeiras eleições, por 410 eurodeputados (Corbett, 2003).

O aumento de legitimidade do Parlamento, conferido pelas eleições diretas, acrescida de uma estratégia para a conquista de maiores competências legislativas, influenciaram no processo de aprofundamento da integração europeia. Em 1986, com a aprovação do Ato Único Europeu, o PE inicia sua trajetória evolutiva de uma Assembleia Consultiva para um parlamento, o qual passa a influir com mais peso no processo legislativo comunitário. Posteriormente, com a assinatura do Tratado de Maastricht, que institui a União Europeia, o Parlamento começa a contar com o critério de co-decisão em determinadas matérias comunitárias, decidindo em conjunto aos Estados-Membros pela aprovação ou rejeição das normas europeias Os tratados europeus posteriores (Amsterdã e Nice) reforçaram sucessivamente esse processo de aumento de matérias decididas pela co-decisão.

A partir da confecção do Tratado de Lisboa o sistema de co-decisão passou a ser denominado de processo legislativo ordinário, ressaltando a pretensão de que todas as matérias, em um dado momento da evolução da UE (cada vez mais próximo), sejam vinculadas a esse 
modelo de procedimento legislativo. A alteração de nomenclatura da co-decisão traz um caráter regular a esse sistema de aprovação legislativa (Medeiros; Campos, 2009). Com essa nova transformação dos tratados europeus, o Parlamento, no âmbito de aprovação legislativa, passa a ser praticamente um colegislador europeu, atuando em pé de igualdade na ratificação de quase todas as matérias da integração europeia, à exceção de temas de política externa, segurança e defesa, ainda regulados pelos sistemas de consulta e cooperação, procedimentos nos quais os Estados-membros mantém o poder decisório.

O desempenho e a importância das eleições europeias não parecem acompanhar a progressiva evolução institucional do $\mathrm{PE}$. $\mathrm{O}$ pleito europeu continua a ser caracterizado como eleições de segunda ordem (Schmitt, 2005). As eleições diretas para o PE seriam secundárias em relação às eleições nacionais, apresentado menos participação do eleitorado e baixa politização da campanha política, focadas em temas políticos nacionais e não europeus. O comportamento dos eleitores que votam é normalmente de descontentamento quando aos partidos dos governos nacionais.
Diferentemente das eleições nacionais, os partidos grandes tendem a ter menos votos que os partidos menores, demonstrando maior ideologização nos votos e maior proximidade do resultado da votação às afinidades ideológicas do eleitorado (Ibidem). Partidos de extrema-esquerda e "verdes" têm recebido mais votos nas eleições europeias do que nacionalmente.

Os eleitores tendem a votar contra os partidos governistas por esses serem mais pró-europeus do que o eleitor médio. Ademais, o contexto das campanhas eleitorais valoriza o sentimento de euroceticismo, trazendo mais votos aos partidos opositores dos governos (Hobolt et al 2008). Embora categorize-se como eleições de segunda ordem, a seleção política dos candidatos pode influenciar nos resultados eleitorais. A escolha de candidatos com maior popularidade, experiência política e imagem positiva para comporem o topo das listas partidárias aumenta os votos para os partidos nacionais que assim agem (Hobolt; Hoyland, 2011).

\section{Gráfico 1}

\section{Apoio às eleições diretas para o Parlamento Europeu (1973-1979)}

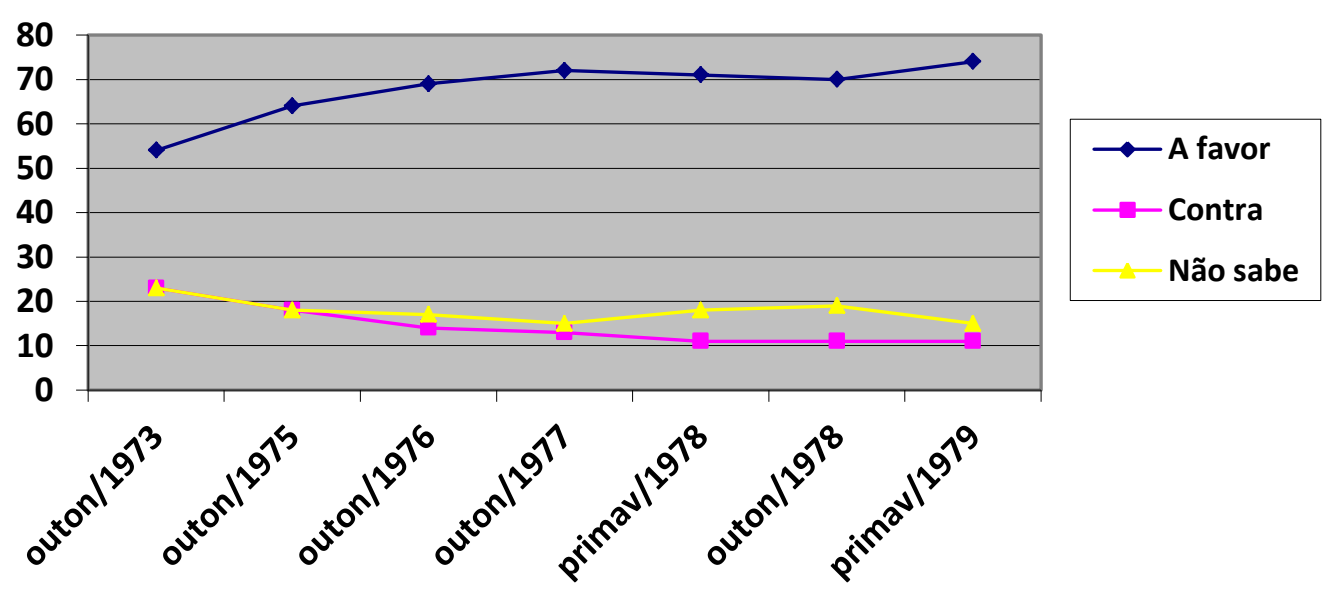

Fonte: elaboração própria, com base em Eurobarômetro (1979). 
Um dado significativo apresentado no relatório do Eurobarômetro de maio de 1979 é o aumento do apoio às eleições diretas para o Parlamento Europeu (Gráfico 1). Houve, ao longo do tempo, aumento do apoio às eleições europeias por parte da população da CEE. De $54 \%$ em 1973, alcançando 74\% momentos antes das primeiras eleições, o apoio às eleições diretas foi crescentemente aumentando, em detrimento do nível de posições contrárias às primeiras eleições, que decaíram de $23 \%$ para $11 \%$. A proximidade das eleições europeias pode ter favorecido o aumento do conhecimento e do apoio à inauguração do primeiro pleito europeu.

\section{Eleições Europeias de 2014: candidaturas e previsões eleitorais}

Novas dinâmicas, conjunturais e institucionais, têm trazido à tona possibilidades de maior politização e de participação nas eleições europeias de 2014. A mudança nas datas das eleições de junho (início das férias de verão no continente europeu) para maio pode favorecer a participação de eleitores que não estavam em seus países durante as eleições (o voto da grande maioria dos países europeus é facultativo). Ademais, a crise nos países da zona do euro e a consequente crise da integração europeia podem incentivar maior mobilização política acerca dos temas de integração regional e não somente em debates políticos nacionais.

As recentes alterações trazidas pelo Tratado de Lisboa, assinado em 2007, porém somente em vigor após as eleições europeias de 2009 (dezembro), trazem modificações institucionais relevantes para o papel político do Parlamento Europeu na UE. Além de aumentar substantivamente os poderes do Parlamento no processo decisório europeu, o Tratado Reformador indica que a nomeação do presidente da Comissão Europeia deve levar em conta os resultados das eleições europeias. A partir de Lisboa, os grupos políticos europeus foram incentivados tanto pelo Parlamento quanto pela Comissão Europeia a apresentar um candidato europeu para a presidência da Comissão.

As famílias políticas europeias são as associações dos partidos políticos de diversas nacionalidades a partir de afinidades ideológicas. Enquanto os partidos nacionais são os responsáveis pelas candidaturas e eleição dos eurodeputados, são os grupos políticos europeus que controlam as discussões, a distribuição de cargos e a agenda das atividades internas do Parlamento Europeu. As três maiores e mais antigas forças políticas europeias são os democratas-cristãos, os socialistas e os liberais, sendo que os dois primeiros historicamente têm compartilhado o maior número de deputados europeus no Parlamento (Bardi; Ignazi, 1999).

Grande parte dos grupos políticos europeus apresentaram candidatos à liderança do executivo europeu: Jean-Claude Juncker pelo Partido Popular Europeu (antigo presidente do Eurogrupo) (PPE); Martin Schulz (Presidente do Parlamento Europeu), da Aliança Progressista dos Socialistas e Democratas (SD); Guy Verhofstadt, líder no PE da Aliança dos Democratas e Liberais pela Europa (ALDE) e Partido Democrático Europeu (PDE); Alexis Tsipras (liderança da Coligação de Esquerda Radical na Grécia) da Esquerda Unitária Europeia/ Esquerda Nórdica; e, por fim, os grupos dos Verdes / Aliança Livre Europeia apresentaram dois candidatos, José Bové (eurodeputado francês e ativista antiglobalização) e Ska Keller (eurodeputada alemã e liderança da juventude verde). A exceção de Tsipras, todos os candidatos atuam ou atuaram em instituições europeias, especialmente no parlamento.

As indicações de lideranças europeias para as eleições do PE podem personalizar e politizar o debate político das campanhas europeias. Seis debates políticos com dois ou mais candidatos à presidência da Comissão ocorreram até a realização das eleições, 
mediados em língua inglesa, alemã e francesa. Diferentemente das campanhas conduzidas pelos partidos políticos nacionais, as campanhas para a presidência da Comissão buscam trazer um caráter europeu aos debates político-eleitorais. As questões respondidas pelos candidatos estavam sempre relacionadas a situações compartilhadas por todos os países europeus, evitando-se discutir a situação política ou econômica particular de um único país. Entre os temas mais mencionados incluem-se superação da crise econômica, criação de empregos, desenvolvimento e renovação da matriz energética e a crise na Ucrânia (Fox, 2014).

Esse vínculo institucional direto entre a composição partidária do Parlamento Europeu com a presidência da Comissão Europeia pode ser visto como mais um sinal da parlamentarização do sistema político europeu (Costa, 2009), anteriormente representada pelo aumento progressivo dos poderes do Parlamento na UE. A influência que o quadro político-ideológico do Parlamento passará a ter na composição da Comissão aproxima-se do sistema parlamentarista adotado nos Estadosmembros, em que o poder executivo é derivado da configuração do legislativo.

A Comissão Europeia também apresentou algumas recomendações para a realização das eleições europeias deste ano. Dentre essas, instou pela facilitação da informação dos cidadãos a respeito da filiação dos partidos nacionais com as famílias políticas europeias, bem como pela indicação dos candidatos à presidência da Comissão. Essas medidas visam à vinculação dos partidos nacionais com as preferências e associações políticas europeias. O próprio Parlamento Europeu, nesse sentido, tem uma atuação pedagógica, ao desenvolver uma campanha neutra, muito mais voltada para ilustrar a importância e o significado do Parlamento na UE, assim como das eleições europeias per se.

\section{Politização e polarização da Europa? Resultados das Eleições Europeias}

O grande destaque das eleições europeias de 2014 foi o papel que os movimentos antieuropeus ou eurocéticos tiveram nas campanhas europeias assim como no resultado das urnas. Fruto do contexto pós-crise europeia, observou-se o aumento dos votos para partidos ou grupos políticos de extrema esquerda e principalmente direita, o que polarizará a composição política interna do Parlamento Europeu. São esses grupos que têm historicamente apresentado um posicionamento nacionalista e cético em relação ao processo de integração da Europa. O Quadro 1, produzido pela revista The Economist, reproduz bem o avanço eurocético dentro do Parlamento Europeu a partir de 2014. Quase dobraram os assentos desses parlamentares em relação à configuração político-europeia das eleições de 2009 (de 56 para 108 eurodeputados). 


\section{Quadro 1}

Partidos Eurocéticos no Parlamento Europeu (2014)

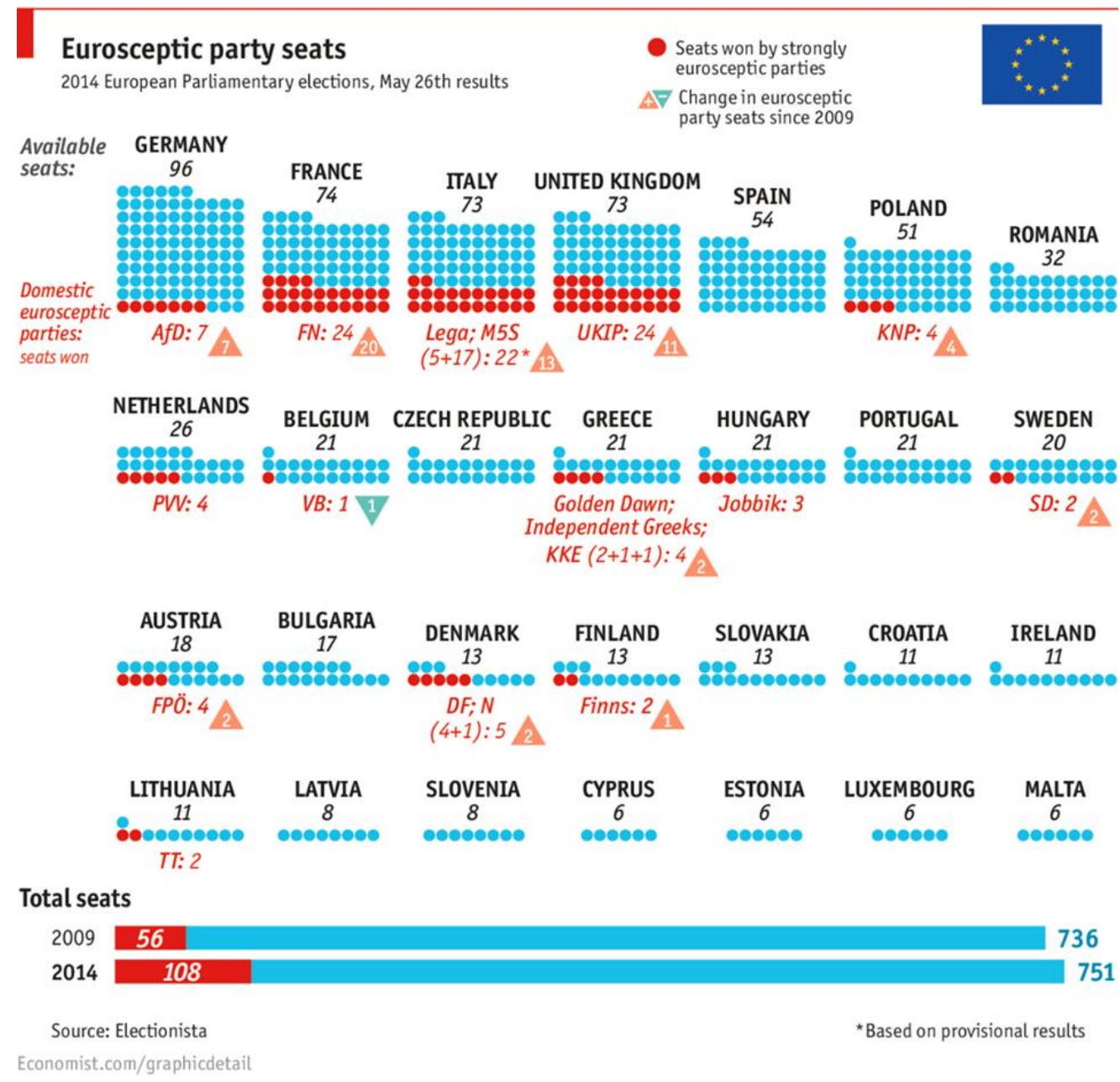

Fonte: The Economist (2014). Disponível em:

http://www.economist.com/blogs/graphicdetail/2014/05/daily-chart-

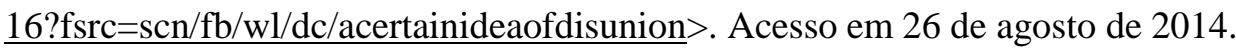

Em países como França e Reino Unido os partidos de extrema direita (Front National e UKIP, respectivamente), com campanhas de teor eurocético, conquistaram o primeiro lugar das urnas e o maior número de cadeiras de seus países (24 assentos cada). Produto do contexto de crise econômica e social, o quadro de polarização ideológica é mais evidente na Grécia, onde a extrema esquerda venceu as eleições, com forte discurso opositor à intervenção da troika (Comissão Europeia, Banco Central Europeu e Fundo Monetário Internacional) na governança econômica do país. Ao mesmo tempo, o partido Golden
Dawn (Aurora Dourada), de extrema direita e com contornos neonazistas, teve um desempenho surpreendente nas eleições, recebendo quase $10 \%$ dos votos gregos (Parlamento Europeu, 2014).

Ainda que a imprensa tenha enfatizado o papel dos eurocéticos nas eleições europeias, o debate político de maior impacto imediato é sobre qual dos dois maiores grupos políticos europeus (democrata-cristãos e socialistas) sairia vencedor das eleições europeias. As últimas pesquisas de opinião indicavam pouca diferença de votos entre essas duas famílias políticas (ligeira liderança dos democrata- 
cristãos), as quais são ambas tradicionalmente euro-otimistas. É essa vitória eleitoral que, de fato, definirá a força política predominante no Parlamento Europeu e consequentemente o nome indicado para Presidente da Comissão Europeia.

Com uma diferença de $4 \%$ dos votos, a bancada dos democrata-cristãos garantiu o maior número de assentos no parlamento europeu (221), enquanto os socialistas mantiveram-se como segundo maior grupo político europeu (191). Importante notar que por conta da grande vitória dos setores eurocéticos nas eleições europeias, o grupo dos conservadores e reformistas tornou-se a terceira maior força política dentro do parlamento, superando, por alguns assentos, o tradicional grupo político dos liberais.

A tendência identificada após os resultados eleitorais de maio é de que os tradicionais grupos políticos europeus (democrata-cristãos, socialistas e liberais) passarão a cooperar mais, com a finalidade de isolar os grupos mais antieuropeus e evitar o impacto desse discurso nas normativas europeias. Embora esses últimos tenham ganhado força a partir das eleições europeias, não são um grupo coeso, apresentando sérias divergências ideológicas (Mahony, 2014b). Exemplo disso foi a rejeição de Nigel Farage, líder do partido britânico UKIP, de qualquer diálogo com o partido vencedor na França, Front National, liderado por Marine Le Pen. Como não se alcançou o número regimental mínimo de eurodeputados de países distintos para fundar um grupo político eurocético novo, o partido de Le Pen, juntamente com seus aliados europeus, não se organizou em uma família política, mantendo seus eurodeputados como membros independentes.

\section{Gráfico 2}

\section{Resultados Eleições Europeias 2014}

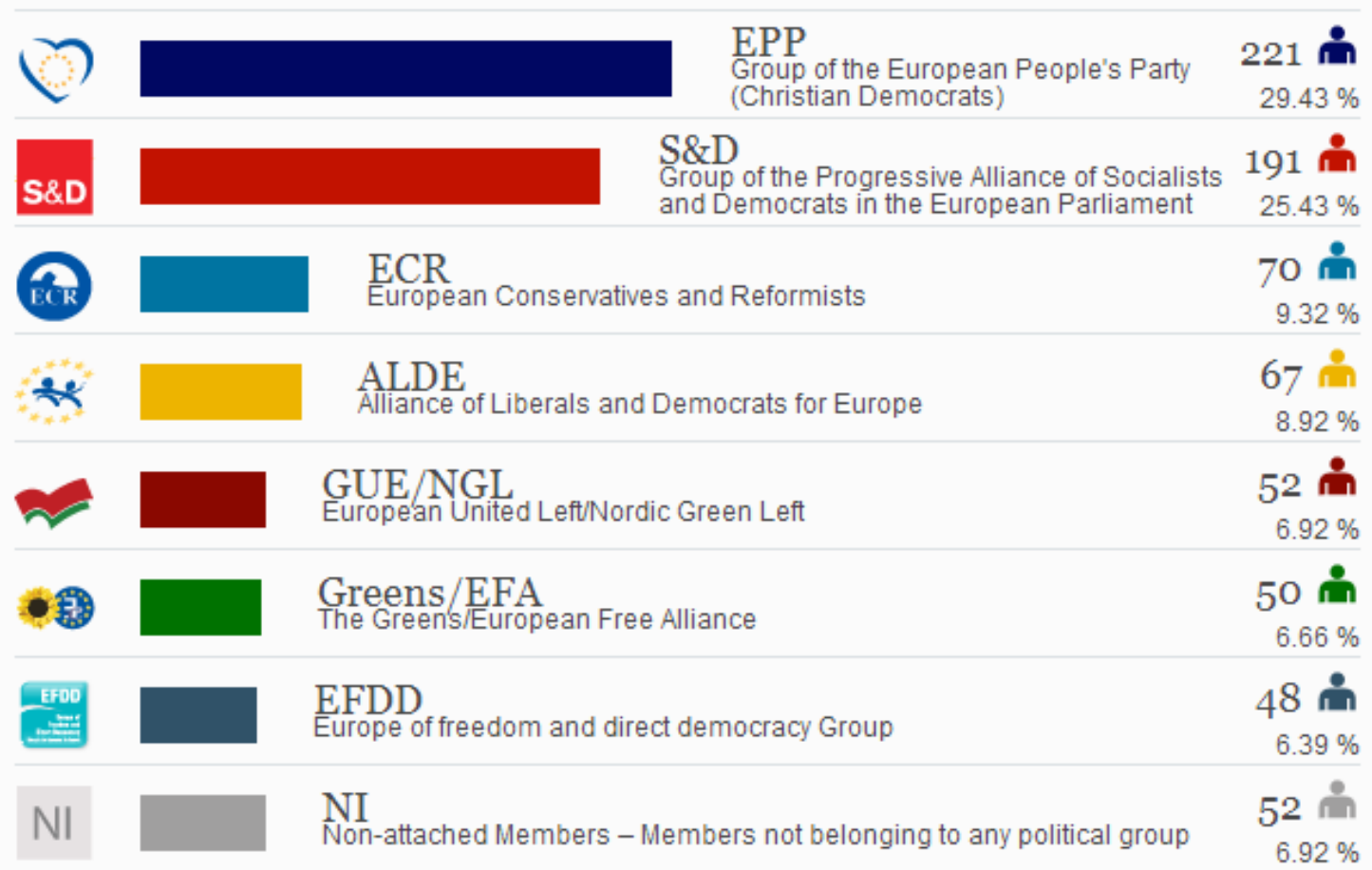

Fonte: European Parliament (2014). Disponível em: < http://www.resultselections2014.eu/en/election-results-2014.html>. Acesso em: 24 de julho de 2014. 
A vitória do Partido Popular Europeu (PPE) nas eleições europeias garantiu a indicação de Jean-Claude Juncker à Presidente da Comissão Europeia. Essa nomeação não foi isenta de críticas dos executivos dos Estados-membros. Houve dificuldade para que os líderes de todos os países aceitassem a figura de Juncker como Presidente da Comissão, especialmente o primeiro-ministro britânico David Cameron, o qual considerou Juncker muito "federalista" para ocupar o cargo após o visível avanço eleitoral eurocético. A partir da cooperação das três forças políticas europeias tradicionais foi possível a obtenção da maioria necessária (422 votos obtidos, mais do que os 376 necessários) para o Parlamento Europeu consentir com a indicação de Juncker como o novo Presidente da Comissão Europeia (Mahony, 2014a).

Tanto o debate anti e pró-Europa quanto a candidatura à Presidente da Comissão trazem à tona a discussão se houve maior politização nas eleições europeias de 2014, tornando o debate mais europeu e menos voltado para temas nacionais, relativizando o conceito de eleições de segunda ordem. A taxa de participação das eleições europeias e os dados da percepção social em relação à importância do voto a nível europeu podem evidenciar o crescimento ou não da mobilização e do interesse dos cidadãos nas eleições.

Nesse sentido, o Gráfico 3 introduz o histórico de participação das eleições europeias, desde o primeiro pleito realizado em 1979, ainda em uma "Europa dos nove". Enquanto de 1979 até 2009 as eleições europeias tiveram um histórico de participação significativamente declinante (de 61,99\% a 43\%), em 2014 o nível geral de participação praticamente se estabilizou, com leve queda para $42,54 \%$. Por outro lado, em países como Alemanha, França, Países Baixos, Grécia e Reino Unido, a taxa de participação nas eleições sofreu aumento, retomando, em geral, os níveis de participação das eleições do início do século XXI. Não é claro se esses dados podem demonstrar uma estabilização dos níveis de participação, mas os resultados nacionais indicam que o avanço dos partidos eurocéticos e sua evidência midiática produziram uma relevante mobilização política na Europa.

\section{Gráfico 3 : Histórico de participação nas eleições europeias (1979-2014)}

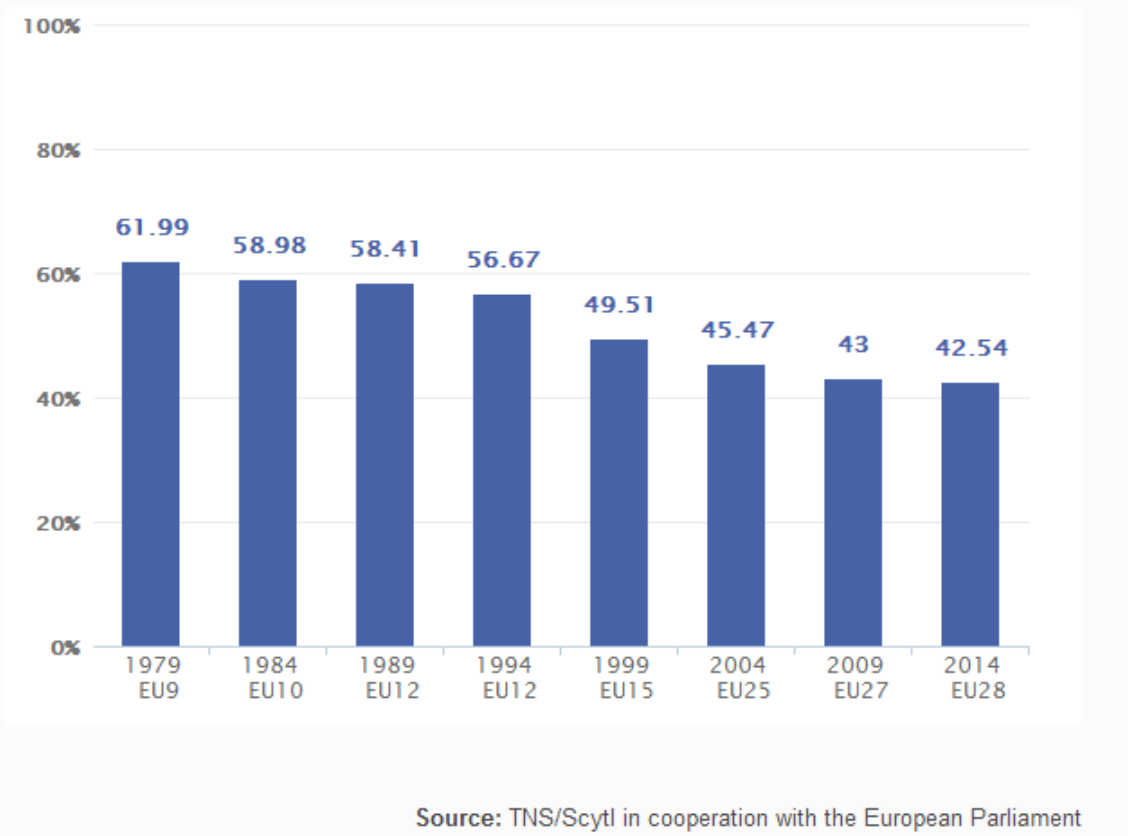

Fonte: European Parliament (2014). Disponível em: < http://www.results-elections2014.eu/en/election-results2014.html>. Acesso em: 24 de julho de 2014. 
Fundamental destacar que as eleições europeias, mesmo com o avanço do euroceticismo partidário dentro das instituições europeias, produziram efeitos na percepção dos eleitores quanto seu papel na integração. Segundo consulta do Eurobarômetro de julho de 2014 (Gráfico 4), aumentou sensivelmente a visão dos cidadãos a respeito da importância que esses têm para definir os rumos da integração. Embora não tenha ultrapassado a taxa de respostas negativas, a visão de que a voz do cidadão importa dentro da UE superou os níveis de todos os anos anteriores analisados. Nota-se que os picos do gráfico situam-se nos anos em que ocorrem eleições europeias (2004, 2009 e 2014), o que permite confirmar a relevância desse pleito na alteração da opinião dos europeus.

\section{Gráfico 4}

D72a.2. Please tell me to what extent you agree or disagree with each of the following statements. My voice counts in the EU - \%EU

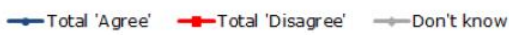

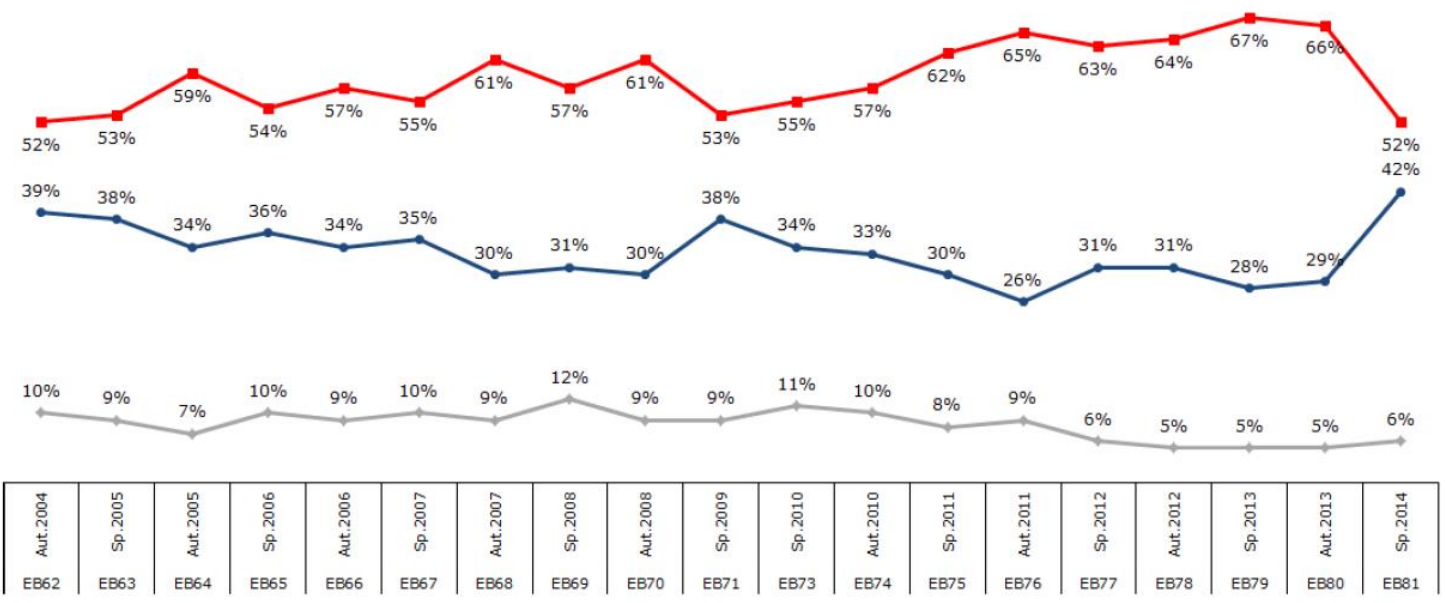

Fonte: Eurobarômetro n. 81, julho, 2014.

A vitória do voto de protesto, o desempenho dos partidos eurocéticos, a ainda baixa participação popular nas urnas (menor do que as eleições nacionais) e o fraco desempenho da maioria dos partidos no governo (importante exceção é a Alemanha) indicam que as eleições europeias mantêm-se como eleições de segunda ordem. A conjuntura econômica e social da Europa e a apresentação de candidaturas à Presidência da Comissão Europeia indicam, todavia, possibilidades de reversão desse quadro. Os dados da última edição do Eurobarômetro reforçam a tendência de que os cidadãos têm percebido que a UE importa e que pode afetar (positiva e negativamente) a vida dos indivíduos europeus. $\mathrm{O}$ avanço das campanhas nacionalistas e eurocéticas, bem como a reação a essas, levou a uma mobilização política inusitada nas eleições europeias, embora os debates (excetuando-se o debate dos candidatos à presidência da Comissão, o qual alcançou algum nível de transnacionalização) restringiram-se a temas e candidatos nacionais, haja vista a relevância dos partidos nacionais na seleção e na campanha eleitoral. 


\section{Conclusões}

Um dos traços institucionais mais marcantes da construção europeia é a parlamentarização do sistema político europeu, notadamente evidenciada pelo sucessivo ganho de competências do Parlamento Europeu desde a sua criação. As eleições europeias favoreceram e legitimaram em grande medida esse empoderamento do parlamento nas decisões comunitárias. Algumas relevantes competências institucionais vieram antes mesmo das primeiras eleições de 1979 (censura à Comissão e fiscalização orçamentária e financeira), porém o parlamento diretamente eleito conseguiu ampliar significativamente seus poderes, tornando, a partir do Tratado de Lisboa, praticamente um co-legislador europeu, em conjunto aos representantes dos EstadosMembros (Conselho da UE).

\section{A indicação dos Spitzenkandidaten} (denominação para os primeiros candidatos das listas eleitorais, importada do sistema político alemão) ao cargo de Presidente da Comissão Europeia, órgão burocrático e executivo da integração, e sua recente aceitação por parte dos Estados-membros e do Parlamento Europeu reforça esse caráter parlamentar introduzido no modelo político europeu. A partir das eleições de 2014, o líder do executivo europeu é derivado diretamente da composição política do parlamento a ser definida pelo resultado das urnas (sistema cada vez mais próximo dos modelos parlamentaristas adotados nacionalmente pelos países do continente). "The majority of MEPs, and through them citizen voters throughout the $E U$, will decide who will head the European Commission, essentially the EU's government" (Bonde 2014, p.1). Ao mesmo tempo, esse novo modelo de seleção do Presidente da Comissão pode trazer maior legitimidade e politização à Comissão Europeia, considerada demasiadamente distante das demandas da população.
Embora as eleições europeias continuem classificadas como eleições de segunda ordem, haja a vista a manutenção da baixa participação popular, da vitória do voto de protesto e da predominância das campanhas políticas nacionais, é possível pelos dados e argumentos apresentados identificar indícios de aumento de politização e mobilização política em nível europeu. Não somente se politizaram mais as discussões políticas europeias, como se tornaram mais polarizadas, a partir do avanço dos votos dos partidos eurocéticos. Um parlamento mais polarizado terá maior dificuldade em construir uma atuação uníssona em diversos temas europeus e internacionais, exigindo maior cooperação das três forças políticas tradicionais. Ademais, certos partidos eurocéticos são avessos aos princípios da integração europeia, além de relativizarem as tradicionais noções de democracia e direitos humanos concebidas no velho continente.

Os parlamentos, ainda que sejam considerados instituições democráticas formais, podem ser instrumentos para a criação de um espaço público regional ou supranacional europeu, que permitam o debate público, a contestação e o controle das políticas da integração. A inclusão de instâncias parlamentares na integração regional não somente aproxima as elites políticas das decisões tomadas no âmbito regional, como constitui um ambiente público propício à informação e à participação da sociedade nas discussões políticas regionais (LUCIANO, 2013). As campanhas eleitorais para o Parlamento Europeu, nesse sentido, evidenciam esse potencial de politização da integração europeia, por meio do exercício da cidadania em escala supranacional.

Esse debate político a nível europeu supõe, inclusive, o questionamento a respeito de qual deve ser o rumo da integração europeia. $O$ crescimento de setores eurocéticos a nível europeu, a saber, demonstra a existência de um posicionamento contrário ao processo de maior integração (direcionado em última ratio à 
federalização da Europa) e favorável a uma redução do grau de integração regional, ou a uma integração seletiva (Europa à la carte). $\mathrm{O}$ quadro ideológico do PE cada vez mais representará essa multiplicidade de opiniões a respeito do futuro da União Europeia, o reproduzirá a pluralidade de visões e percepções dos cidadãos europeus.

Independentemente do resultado eleitoral, as eleições europeias devem tornar o peso do Parlamento Europeu nas políticas europeias mais significativo, principalmente por conta do vínculo que o futuro Presidente da Comissão terá com a configuração política do
Parlamento. Existe a expectativa de que essa instituição parlamentar passe a exercer maior influência na formulação das decisões europeias e não somente em sua ratificação. Um Parlamento mais importante e poderoso pode ser interessante, inclusive, para países fora da Europa, como o Brasil. A existência de uma delegação do Parlamento Europeu para relações com os países do Mercosul e a recente criação de uma delegação exclusiva para as relações com o Brasil podem se transformar em mecanismos de diálogo relevantes para o contato do país com as instituições que influenciam no processo decisório europeu.

\section{Referências}

Bardi, L.; Ignazi, P. (1999). Il Parlamento Europeo. Bolonha: Il Mulino.

Bonde, Jens-Peter (2014). 'The day we got EU parliamentarism'. EU Observer, 15th Jul. Disponível em: <http://euobserver.com/opinion/124968>. Acesso: 04 de ago. 2014.

Brunkhorst, H. (2006). 'Unificação desigual: Poder transnacional e crise de legitimação na Europa contemporânea'. Novos Estudos, n.76, Novembro.

Corbett, R.; Jacobs, F. \& Shackleton, M. (2003). 'The European Parliament at Fifty: A View from the Inside'. JCMS, 41(2).

Costa, O. (2009). 'Le parlement européen dans le système décisionnel de l’Union européenne: la puissance au prix de l'illisibilité'. Politique européenne, 28(2).

Eurobarômetro (1979). N. 11, maio, Bruxelas.

Eurobarômetro (2014). N. 81, julho, Bruxelas.

Fox, B. (2014). 'Left and Right trade blows on economy in EU election debate'. EU Observer, 16th May. Disponível em: 〈http://euobserver.com/eu-elections/124157> . Acesso em: 04 de Agosto de 2014.

Goetze, S. \& Rittberger, B. (2010). 'A matter of habit? The sociological foundations of empowering the European Parliament'. Comparative European Politics, 8(1), pp. 37-54.

Hobolt, S.; Spoon, J. \& Tilley J (2008). 'A Vote Against Europe? Explaining Defection at the 1999 and 2004 European Parliament Elections'. B.J.Pol.S.,39.

Hobolt. S. \& Hoyland, B. (2011). 'Selection and Sanctioning in European Parliamentary Elections'. B.J.Pol.S.,41. 
Levi, M. (1966). 'Physionomie d'un Parlement européen’. Politique étrangère, n¹, pp. 86-97.

Lodge, J. (1994). 'The European Parliament and the Authority-Democracy Crises'. Annals of the American Academy of Political and Social Science, Vol. 531, The European Community: To Maastricht and beyond, Jan., pp. 69-83.

Luciano, B. T. (2013). Democratizando a integração: eleições diretas para o Parlamento Europeu e do Mercosul. Dissertação de Mestrado. Instituto de Relações Internacionais, Universidade de Brasília, Brasília.

Mahony, H. (2014a). 'Juncker elected: promises more social EU, more political commission'. EU Observer, 15th, July. Disponível em: 〈http://euobserver.com/political/124980>. Acesso em: 04 de ago. 2014.

. (2014b). 'Main EP groups debate closer cooperation, isolating far right'. EU Observer, 12th, June. Disponível em: 〈http://euobserver.com/eu-elections/124561〉. Acesso em: 04 de ago. 2014.

Medeiros, M.; Campos, C. (2009). 'União Europeia, reformas institucionais e déficit democrático: uma análise a partir do mecanismo de co-decisão'. Revista Brasileira política Internacional. 52(1), pp.29-52.

Nugent, N. (1999). The Government and Politics of the European Union. Durham: Duke University Press.

Parlamento Europeu (2014). Resultado das Eleições Europeias de 2014. Disponível em: $<$ http://www.resultados-eleicoes2014.eu/pt/seats-member-state-absolut.html >. Acesso em: 01 de ago. 2014.

Schmitt, H. (2005). 'As eleições de Junho de 2004 para o Parlamento Europeu: ainda eleições de segunda ordem?'. Análise Social, XL(177), pp.765-794. 